\title{
Evolução das inundações no sul do Brasil: o caso da Bacia Hidrográfica do Rio do Peixe
}

\author{
Elaine Cristina dos Santos ${ }^{1}$, elaine-cristinas@hotmail.com; Márcio de França Santos ${ }^{2}$
}

\begin{abstract}
RESUMO
Os desastres socioambientais são muito recorrentes no estado de Santa Catarina, região do sul do Brasil, principalmente os que são relacionados com geomorfologia e pluviosidade como, deslizamentos, enxurradas, inundações e estiagens. Com base nisso, este estudo propôs uma análise aplicada às inundações na bacia hidrográfica do Rio do Peixe (meio-oeste catarinense) e relacionando com o aumento populacional, pluviosidade, oscilação da temperatura do Pacífico e características hipsométricas. Para a elaboração da análise foram levantados os dados de inundações registrados pelo relatório de avaliação de danos (AVADAN) e em correlação ao número de habitantes da região, segundo a série histórica do IBGE, além dos períodos de oscilação da temperatura do Pacífico, conforme a National Oceanic and Atmospheric Administration. Os dados mostraram que as inundações mudaram de comportamento desde os anos 1980 até o ano de 2010, onde as inundações graduais se tornaram menos frequentes e as inundações bruscas mais frequentes. Nos períodos de El Niño as inundações foram mais recorrentes, porém com maior ocorrência de inundação do tipo gradual, enquanto que nos períodos de La Niña as inundações graduais foram menos recorrentes e as bruscas aconteceram com mais assiduidade. Por outro lado, a população dos municípios da área de estudo também aumentou gradualmente de forma que acompanharam os aumentos dos registros de inundações.
\end{abstract}

Palavras chave: inundação gradual, inundação brusca, El Niño-oscilação Sul, crescimento populacional.

\section{Evolution of the floods in southern Brazil: the case of Rio do Peixe Watershed}

\begin{abstract}
In Santa Catarina, which is located in southern Brazil, environmental disasters are recurrent. In particular those related to geomorphology and rainfall, such as landslides, floods, high precipitation, and droughts. This study proposes an analysis applied to the inundation in Rio do Peixe's watershed (midwestern Santa Catarina) and related to the population increase, rainfall, South Pacific Oscillation temerpature and hypsometric characteristics. For the analysis, data from floods recorded (AVADAN) was collected and correlated to the number of inhabitants of the region, according to the historical series of the IBGE and additionally to the periods of the Pacific temperature fluctuation, according to the National Oceanic and atmospheric Administration. The data showed that the floods pattern changed from 1980 to 2010, where gradual inundations became less frequent and sudden inundations occurred in greater numbers. During El Niño periods inundations were most frequent but higher occurrences of progressive flood and in La Niña periods the progressive flooling were less recurrent. However, the population of the municipalities of the study area also increased gradually, paralelling increases in flood incidents.
\end{abstract}

Keywords: gradual inundation, sudden inundation, El Niño-Southern Oscillation, population increase.

Recibido el 30 de mayo de 2016; aceptado el 06 de julio de 2016.

\footnotetext{
Programa de Pós-Graduação em Geografia, Universidade Federal de Santa Catarina, Florianópolis, Brasil. Campus Universitário Trindade. Caixa Postal 476. Florianópolis - SC. 88.040 - 970.

2 Programa de Licenciatura em Geografia, Universidade Federal de Santa Catarina, Florianópolis, Brasil.
} 


\section{INTRODUÇÃO}

As inundações são os desastres naturais mais comuns, que afetam pessoas, infraestruturas e o meio ambiente, principalmente por abrangerem áreas extensas. São ocasionadas pela alta disposição de água no ambiente originárias de chuvas em excesso, transbordamento do curso ou corpo d'água, degelo, altas de maré, todas em um curto período, assim comprometendo a eficácia do escoamento superficial (OAS 1991).

Ao longo dos últimos anos as inundações têm se tornado cada vez mais severas, devido ao aumento de sua intensidade e frequência (KRON 2002 em KOBIYAMA et al. 2009). Tal aumento de ocorrência de desastres por inundações pode estar associado, principalmente, ao crescimento populacional e a origem ou continuidade de ocupações de planícies de inundações (KOBIYAMA et al. 2009).

As inundações podem ser graduais ou bruscas. As graduais estão associadas a longos períodos de chuvas contínuas. Nesse tipo de inundação, o rio se eleva aos poucos e previsivelmente, onde o nível de enchente mantém-se estável por algum tempo e depois escoa gradativamente. As inundações bruscas estão associadas a chuvas intensas e concentradas, causando a elevação súbita do nível d'água e escoando rapidamente (CASTRO 2007).

Um dos desastres que mais causa vítimas na América do Sul são as inundações, muito recorrentes em todos os países desse continente e são classificadas como ameaça predominante ou de maior impacto para a Argentina, Bolívia, Chile, Colômbia, Equador e Peru (KHAMIS \& OSORIO 2013).

No Brasil durante o período de 1991-2000 as inundações graduais e bruscas ficaram entre os desastres mais recorrentes no território nacional, atrás apenas das secas e estiagens. Registraram-se mais danos com as inundações bruscas na região sul, principalmente nos estados do Rio Grande do Sul e Santa Catarina, nas mesorregiões inseridas na bacia hidrográfica do rio Uruguai. Quanto às inundações graduais, a região sudeste apresentou maior registro, seguida pela região sul do Brasil (UFSC/ CEPED 2012).

De acordo com SANTA CATARINA (2006) e HERRMANN (2014), as inundações são os desastres que afetam com maior frequência o estado de Santa Catarina, atingindo principalmente a população urbana que ocupa as áreas ribeirinhas. Os mesmos autores relatam que as planícies costeiras e as bacias hidrográficas de grandes rios são as mais afetadas.

Dentre as bacias de grandes rios está a do Rio do Peixe, situada no meio-oeste de Santa Catarina (Fig. 1), uma das áreas de extrema importância na produção agrícola do estado. HERRMANN (2014) constataram 192 decretos municipais e Relatórios de Avaliação de Danos (AVADANs) referentes a inundações nos municípios que fazem parte desta bacia, de 1980 a 2010. Por essa razão buscou-se avaliar a frequência e os tipos de inundações que atingiram a bacia hidrográfica do Rio do Peixe no período de 1980 a 2010, por meio na análise da influência do El Niño-Oscilação Sul, bem como também com o crescimento populacional e a morfologia do relevo.

O El Niño-Oscilação Sul (ENOS) é um fenômeno natural de flutuação da temperatura do oceano Pacífico Equatorial. Trata-se de um fenômeno de interação atmosfera-oceano, gerado a partir de alterações dos padrões normais da Temperatura da Superfície do Mar e dos ventos alísios na região do Pacífico Equatorial. Este fenômeno é conhecido por ser uma força dominante que causa variações no clima regional. O ENOS pode ser quantificado pelo Índice de Oscilação Sul, com valores negativos e positivos, caracterizando eventos de La Niña e El 
LOCALIZAÇÃO DA BACIA HIDROGRÁFICA DO RIO DO PEIXE, SC - BRASIL

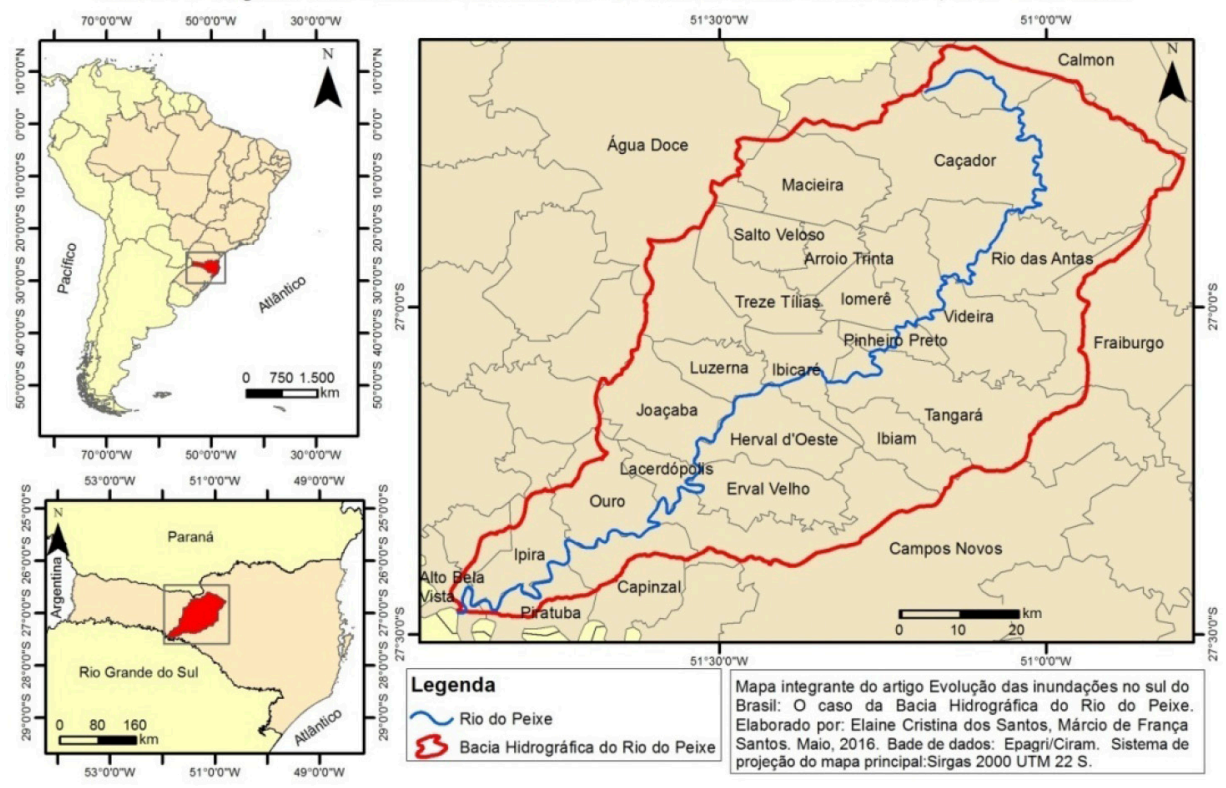

Fig. 1. Localização da área de estudo. Elaborado pelos autores (2016).

Fig. 1. Location of the study area. Prepared by the authors (2016).

Niño, respectivamente. Dentre as alterações que podem ocorrer no clima, para o Sul do Brasil pode-se destacar precipitações abundantes e aumento na temperatura média durante os eventos de El Niño e períodos secos durantes os de La Niña (CPTEC/ INPE 2016).

\section{TUCCI \& BERTONI (2003) ao} desenvolverem sua pesquisa sobre as inundações urbanas na América do Sul relacionaram-nas ao desenvolvimento urbano e populacional nos países sulamericanos e consideram como elementos responsáveis pela vitimização por inundação: (i) há pouca ou nenhuma restrição do Plano Diretor Urbano quanto ao loteamento e ocupação em área em risco de inundação, (ii) invasão das área ribeirinhas que pertencem ao poder público por famílias de baixa renda e (iii) ocupação de áreas de médio risco, com ocorrências menos frequentes do sinistro mas passíveis de perdas significativas.
Conforme aumenta a área urbana ocorre o aumento das vazões máximas e da sua frequência por causa do aumento da capacidade de escoamento pelos condutos e canais ou ainda pela impermeabilização das superfícies, aumento da produção de sedimentos devido à falta de proteção das superfícies e à produção de resíduos sólidos, deterioração da qualidade da água superficial e subsuperficial, construções civis e de infraestrutura que interrompam ou alterem a circulação das águas superficiais, obstrução de canais, projetos de drenagem mal planejados e diminuição de espaços de escoamento por aterro e terraplanagem (TUCCI \& BERTONI 2003).

\section{MATERIAIS E MÉTODOS}

Para a construção deste trabalho foi realizado um levantamento bibliográfico das inundações registradas na Bacia Hidrográfica do Rio do Peixe e aderiu-se 
os dados sistematizados por HERRMANN (2014) no Atlas de Desastres Naturais do Estado de Santa Catarina, período de 1980 a 2010. Tais dados derivaram dos Relatórios de Avaliação de Danos (AVADANs) e decretos municipais. A partir destes dados organizou-se uma planilha com os dados disponibilizados pelo Atlas de Desastres Naturais, por tipo de inundação (gradual ou brusca), ano de ocorrência e município atingido.

A quantidade e o tipo de inundações registradas foram comparadas com os dados do El Niño-Oscilação Sul (ENOS), disponibilizados pela NATIONAL OCEANIC AND ATMOSPHERIC ADMINISTRATION (NOAA 2014), buscando associações entre o número de registros e o tipo de inundações com os períodos influenciados por El Niño e $\mathrm{La}$ Niña.

As influências antrópicas também foram avaliadas na caracterização do tipo e na quantidade de inundações que atingiram os municípios da Bacia do Rio do Peixe. Utilizou-se os censos demográficos dos anos de 1980, 1991, 2000 e 2010 provenientes do Instituto Brasileiro de Geografia e Estatísticas (IBGE), e comparou-se o uso e cobertura do solo das folhas topográficas de Caçador (IBGE 1973), Joaçaba (IBGE 1976a) e Videira (IBGE 1976b) com o mapa de uso e ocupação do solo realizado pela GEOAMBIENTE/FATMA (2008).

Para complementar a análise das inundações, utilizou-se o mapa altimétrico da bacia do Rio do Peixe elaborado por LOPES (2012), e as folhas topográficas de Caçador (IBGE 1973), Joaçaba (IBGE 1976a) e Videira (IBGE 1976b), que além das informações topográficas apresentam os rios tributários do Rio do Peixe e os centros urbanos. O mapa utilizado, elaborado por LOPES (2012), recebeu algumas modificações (localização dos centros urbanos e ranking dos municípios mais atingidos por inundações) empregadas para identificar as áreas que possivelmente concentram os maiores níveis de água pela disposição do relevo, as planícies de inundação e as áreas urbanas, podendo assim explicar a razão de alguns municípios possuírem mais registros de inundações que outros.

\section{RESULTADOS}

\section{Levantamento dos registros de inundações}

Ao analisar as inundações bruscas e graduais registradas por HERRMANN (2014) (Fig. 2), nota-se que na década de 80 eram constantes as inundações graduais, um total de 70 para apenas 7 de inundações bruscas. Nesta mesma década, apenas nos anos de 1985 e 1986 não foram registradas inundações, nos demais anos foram registradas de 1 a 5, com exceção de 1983.

Na década de 90 somaram-se um total de 74 inundações e apesar do pequeno aumento em relação à década anterior, é notória a diferença na frequência de cada tipo de inundação. Os registros de inundações graduais se tornaram menos frequentes enquanto as inundações bruscas aumentaram significativamente. Apenas em 1991 e 1999 não foram registradas inundações e os anos que mais houve registros foram 1990 (20 registros), 1992 (14) e 1997 (16).

De 2000 a 2010 foram registradas 41 inundações. Nota-se uma inversão nas ocorrências de inundações graduais e bruscas. A partir de 2001 não foram registradas inundações graduais em nenhum ano, enquanto que as inundações bruscas passaram a ser dominantes, com exceção de 2006, todos os anos registraram inundações bruscas.

Resumidamente, de 1980 a 1989, as inundações graduais representavam no Vale do Rio do Peixe $91 \%$ dos registros de inundações enquanto as inundações bruscas 


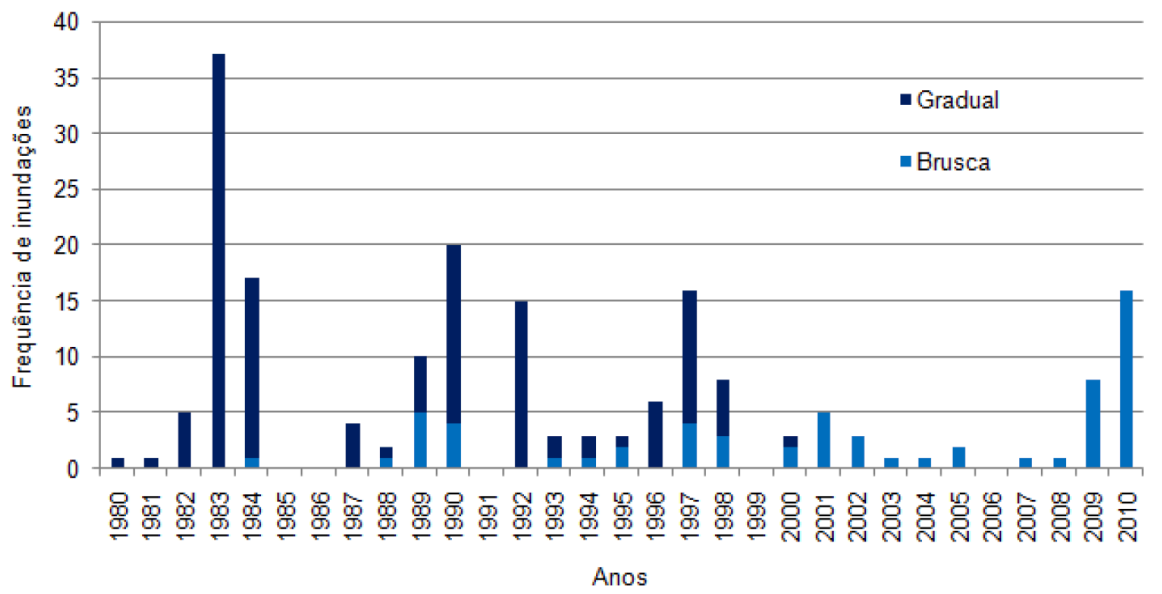

Fig. 2. Registro de inundações graduais e bruscas ocorridas na bacia do Rio do Peixe entre 1980 a 2010. Adaptado de HERRMANN et al. (2014).

Fig. 2. Registration gradual and sudden flood in the Rio do Peixe catchment between 1980 and 2010. Adapted from HERRMANN et al. (2014).

representavam 9\%. De 1990 a 1999 as inundações graduais caíram, representando $73 \%$ dos registros e as bruscas tiveram um significativo aumento, passando para $27 \%$. No período de 2000 a 2010 as inundações registradas foram $97,5 \%$ bruscas e $2,5 \%$ graduais.

\section{Os tipos de inundações e o El Niño- Oscilação Sul}

$\mathrm{Na}$ década de 80 considerável parte dos registros de inundações graduais ocorreu em fases de El Niño, com destaque para o ano de 1983, que registrou 37 inundações desta categoria sob influência de El Niño forte. Porém, para este mesmo período, os maiores números de registros de inundações bruscas ocorrem sob influência de La Niña e fases neutras (Fig. 3A e 3B).

Já na década de 90 os anos que mais houve registros de inundações graduais foram 1990, 1992 e 1997 com 16, 14 e 12 registros, sob efeito de períodos neutros, El Niño moderado e El Niño forte, respectivamente. Para os eventos nas fases de La Niña, o número de inundações foi pequeno quando se comparado aos que ocorreram nas fases quentes do ENOS.

Destaca-se que de 2000 a 2010 houve um aumento na frequência de inundações associadas a eventos de La Niña, normalmente de intensidade fraca, assim como o aumento de inundações bruscas para este mesmo período, que nos anos 1980 e 1990 eram poucos.

\section{Crescimento populacional e o uso e ocupação do solo}

Segundo o censo demográfico do IBGE (1980; 1991; 2000; 2010), pode-se constatar de que houve um aumento da população dos municípios na bacia do Rio do Peixe. Em 1980 a população foi estimada em 240 mil habitantes e em 2010 cerca de 340 mil habitantes. Comparou-se este dado com o aumento de ocorrências de inundações bruscas (Fig. 4), já que o crescimento populacional provoca modificações no uso e ocupação do solo, consequentemente afetando o escoamento das águas. 


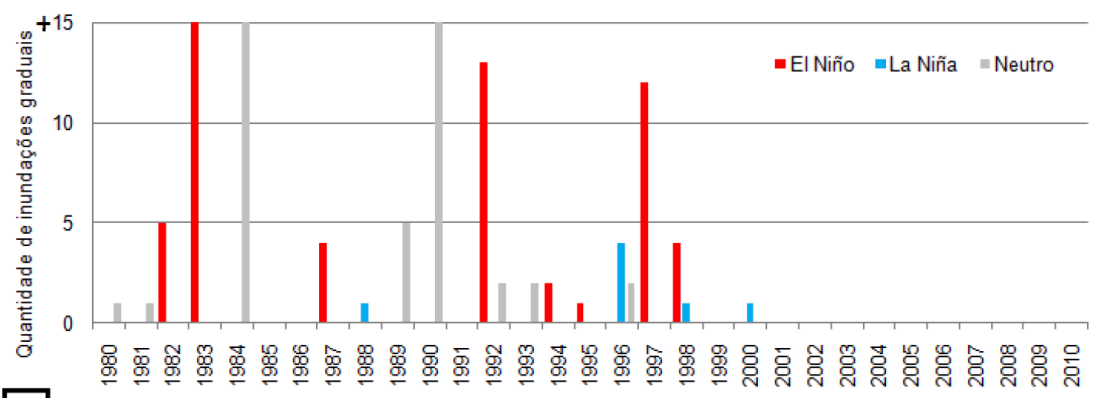

A Anos

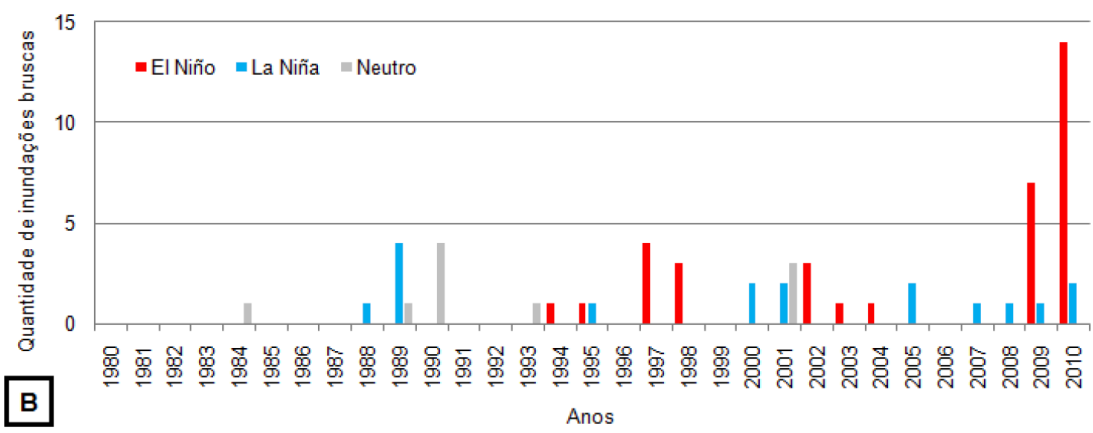

Fig. 3A. Quantidade de inundações graduais registradas de 1980 a 2010 sob diferentes influências do ENOS.

Fig. 3B. Quantidade de inundações bruscas registradas de 1980 a 2010 sob diferentes influências do ENOS. Adaptado de HERRMANN (2014); NOAA (2014).

Fig. 3A. Number of registered gradual flood 1980-2010 under different influences of ENSO. Fig. 3B. Number of registered sudden inundation from 1980 to 2010 under different influences of ENSO. Adapted from HERRMANN (2014); NOAA (2014).

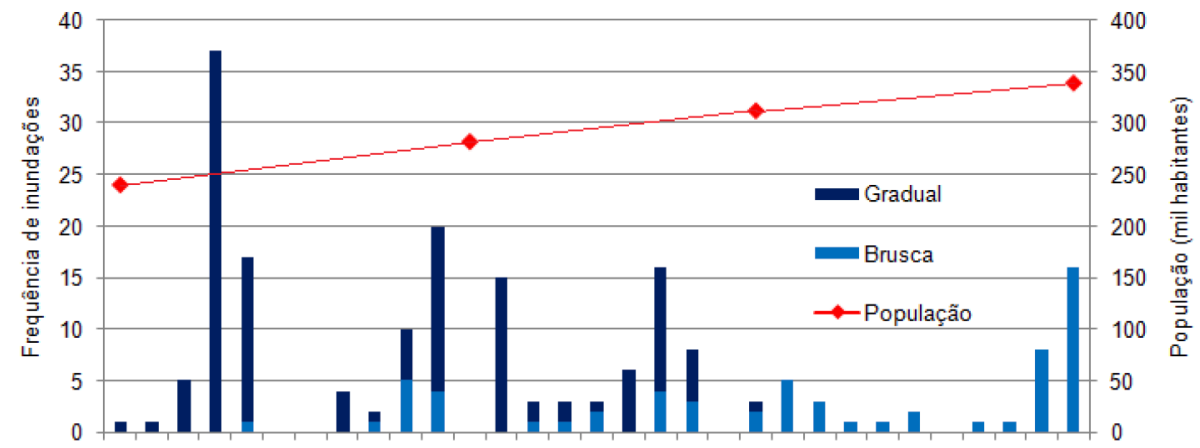

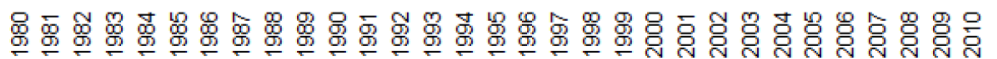

Anos

Fig. 4. Comparação dos registros de inundações graduais e bruscas com os dados de população dos municípios integrantes da área de estudo. Adaptado de HERRMANN (2014) e IBGE (1980; 1991; 2000; 2010).

Fig. 4. Comparison of records of gradual and sudden flood with the population data of the municipalities of the study area. Adapted from HERRMANN (2014) and IBGE (1980; 1991; 2000; 2010). 
Quanto ao uso e ocupação do solo, ao comparar as cartas topográficas do IBGE $(1973$; 1976) com o levantamento da GEOAMBIENTE/FATMA (2008), constatou-se que as práticas agropecuárias já estavam presentes em grande parte da bacia em questão desde a década de 70 e já existia ocupação às margens do rio do Peixe, não havendo grande diferenciação do uso e ocupação atual do solo (Fig. 5).

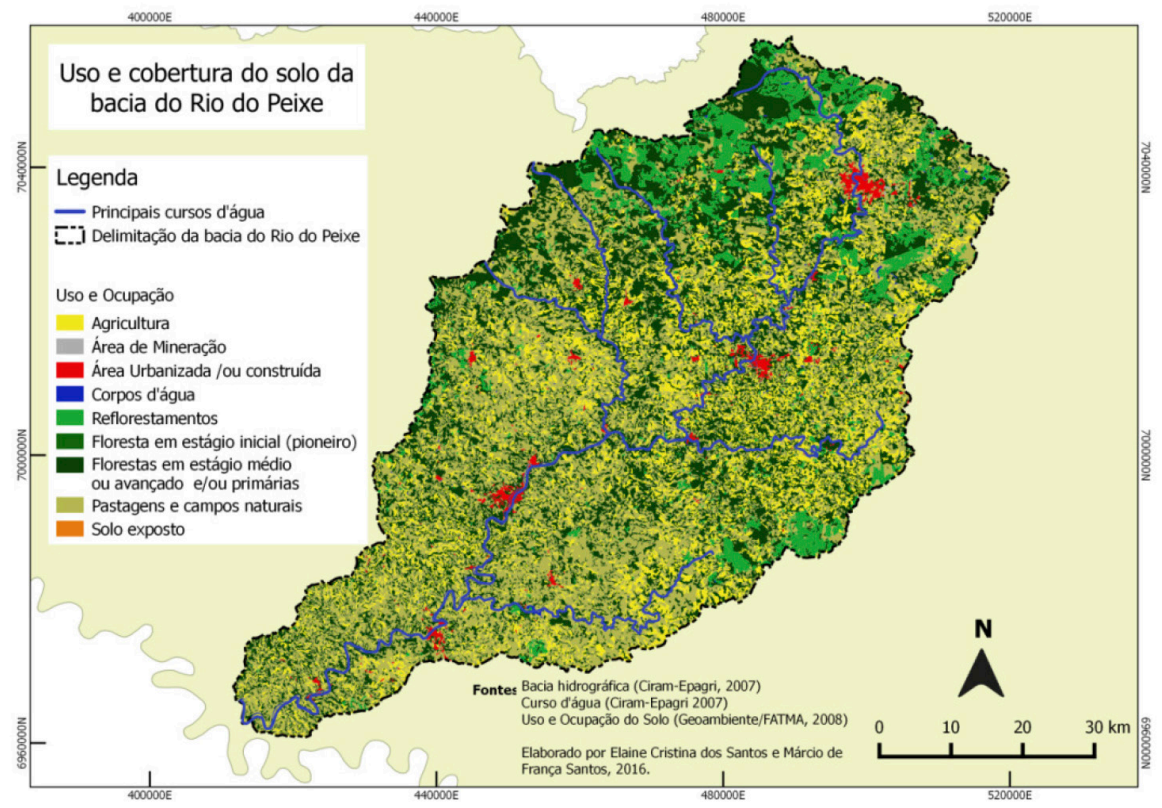

Fig. 5. Uso e cobertura do solo da área de estudo. Adaptado de GEOAMBIENTE/FATMA (2008).

Fig. 5. Use and land cover in the study area. Adapted from GEOAMBIENTE/FATMA (2008).

\section{Inundação e geomorfologia da bacia do Rio do Peixe}

A partir dos dados levantados por HERRMANN (2014), a identificação das manchas urbanas e do mapa altimétrico da bacia elaborado por LOPES (2012), foi possível identificar os municípios que foram mais afetados pelas inundações registradas, além da compreensão trazida pela análise da morfologia da bacia afetando na ocorrência de inundações (Fig. $6)$.

O município de Caçador está situado em altitudes elevadas, no alto vale do Peixe, e ficou em segundo lugar por registros de inundações. Municípios como Tangará, Herval d'Oeste, Videira, Pinheiro Preto e Ibicaré estão situados no médio vale e também nos setores côncavos da bacia. Além disso, os seus centros urbanos estão às margens do rio, nas chamadas planícies de inundação.

Joaçaba e Herval d'Oeste são municípios vizinhos separados pelo Rio do Peixe, mas o primeiro apresenta mais registros de inundação que o segundo. Os municípios situados na foz do Rio do Peixe Alto Bela Vista, Ipirá e Piratuba, estão entre os que menos sofrem com inundações, mesmo estando localizados no Baixo Vale, com baixas altitudes. 


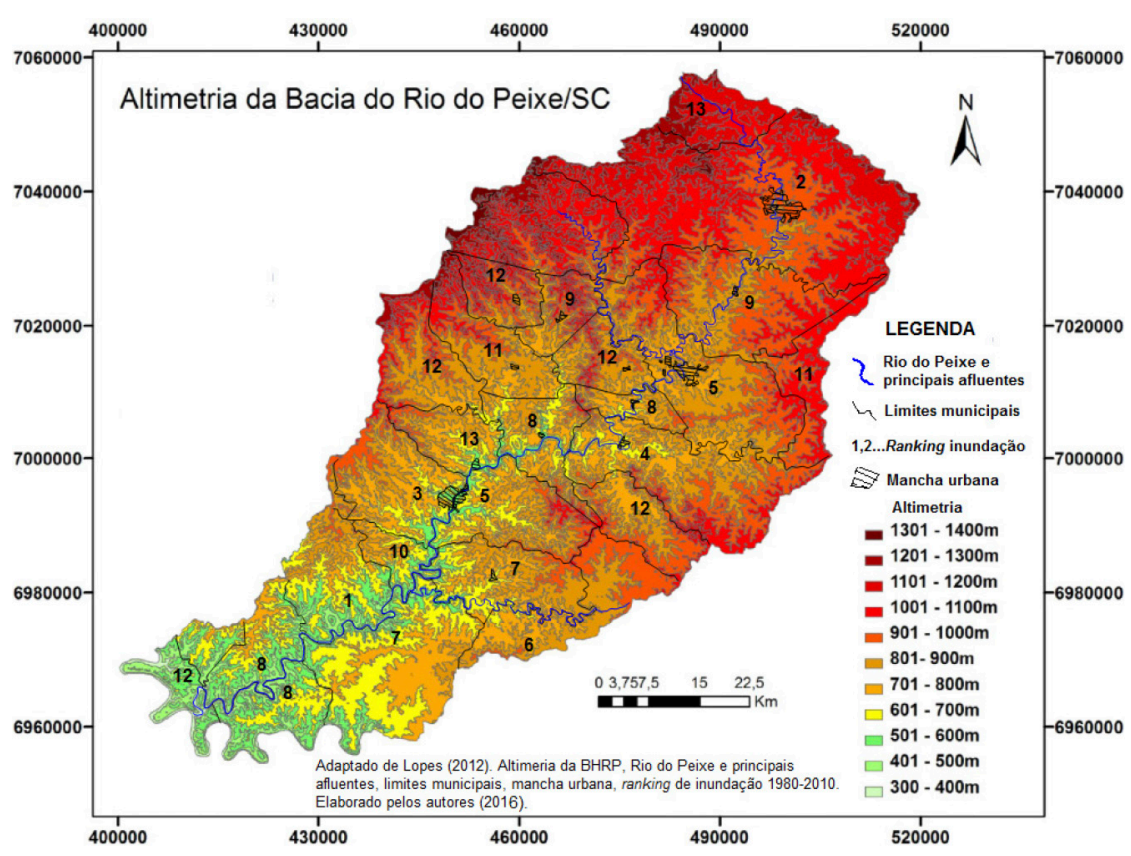

Fig. 6. Altimetria da Bacia do Rio do Peixe e ranking de municípios inundados baseado nos registros de 1980 a 2010. Adaptado de LOPES (2012); HERRMANN (2014).

Fig. 6 Altimetry of Rio do Peixe catchment and ranking flood municipalities based on records from 1980 to 2010. Adapted from LOPES (2012); HERRMANN (2014).

\section{DISCUSSÃO}

Comparação do histórico de inundações graduais e bruscas com o El NiñoOscilação Sul

Comparando os registros de inundações graduais e bruscas na bacia do Rio do Peixe, de 1980 a 2010, com as fases positivas e negativas do El Niño-Oscilação Sul percebe-se que sob o efeito do El Niño houve o dobro de inundações graduais sobre as bruscas, porém quando se tratou da La Niña os registros de bruscas somaram o dobro das graduais.

O El Niño provoca longo período de chuvas na região Sul do Brasil, por isso pode-se notar sua relação com as inundações graduais, já que estas estão associadas a chuvas contínuas. A La Niña pode provocar seca no Sul do Brasil com chuvas concentradas, assim coincidindo com maiores registros de inundações bruscas do que graduais, pois as primeiras costumam ocorrer devido a chuvas intensas e concentradas (CASTRO 2007; MENDONÇA \& DANNI-OLIVEIRA 2007).

Entretanto, apesar de ter ocorrido mais inundações bruscas do que graduais em fases de La Niña, os efeitos do El Niño parecem ser mais importantes para a ocorrência de inundações em geral na Bacia do Rio do Peixe. Das inundações bruscas $27 \%$ foram em fases de La Niña, $56 \%$ em fases de El Niño e $16 \%$ em fases neutras, enquanto que as graduais foram 5\%, 60\% e $35 \%$, respectivamente. Por isso buscouse associar este aumento das inundações bruscas com outros fatores que podem 
ajudar a alterar o tipo de inundação, como o aumento da população que gera aumento de áreas impermeáveis e modificações do escoamento da água.

\section{As inundações e os fatores antrópicos}

Ao analisar os dados da população (IBGE 1980; 1991; 2000; 2010) dos municípios inseridos na bacia do Rio do Peixe, nota-se um aumento da população a cada década e acompanhando este ritmo estão os registros de danos por inundações bruscas. Tal fator pode ser um indicativo de que o crescimento da população e da cidade aumentou os elementos que condicionam as inundações nesta bacia, conforme a pesquisa de TUCCI \& BERTONI (2003) para as maiores cidades da América do Sul. Entretanto, não houve significativa alteração na cobertura e uso do solo, marcada principalmente pelas práticas agrícolas.

\section{Morfologia da bacia e os rankings de inundação}

Devidoà morfologia da bacia, as inundações no alto vale decorreriam do abastecimento por chuvas, enquanto que no médio e baixo vale as inundações seriam decorrentes além da própria chuva, do escoamento das águas pluviais, transferindo as inundações para esses setores do vale, onde estão situados os municípios de Joaçaba e Ouro, alguns dos mais atingidos por inundações (SPINELLI 2012; HERRMANN 2014).

O fato do município de Caçador estar situado no Alto do Vale do Rio do Peixe e ter ficado em segundo lugar por registros de inundações têm explicação em parte fundamentada na geomorfologia: o centro da cidade está em uma parte côncava da bacia, em uma seção de baixas altitudes, áreas naturalmente receptoras de grande volume d'água.
Casos semelhantes podem ser vistos em Tangará, Herval d'Oeste, Videira, Pinheiro Preto e Ibicaré. Além de estarem nos setores côncavos, os centros urbanos estão às margens do rio do Peixe, nas chamadas planícies de inundação. Estas planícies acompanham os cursos de água, fazendo parte do vale fluvial, áreas periodicamente inundadas e consideradas o leito maior do rio quando há enchentes (CHISTOFOLETTI 1980).

Joaçaba apresenta mais registros de inundação do que Herval d'Oeste, que é o município vizinho separado pelo próprio rio do Peixe. Isto se deve ao fato de que Herval d'Oeste está situado em áreas mais altas e devido à existência do Rio do Tigre que corta a área urbana de Joaçaba. Os municípios situados na foz do Rio do Peixe Alto, como Bela Vista, Ipirá e Piratuba, estão entre os que menos sofrem com inundações, mesmo estando localizados no Baixo Vale, com baixas altitudes. Em parte é verdade de que há esta influência geomorfológica, mas os registros de inundações aqui tratados (AVADANs e decretos municipais) são feitos quando cidades são atingidas, assim, como centros urbanos se estabelecem nas proximidades dos rios, torna-se difícil dizer se apenas os aspectos geomorfológicos são os de maior importância para propiciar os desastres. Deve-se levar em consideração todos os fatores possíveis, desde os aspectos físicos até os socioeconômicos.

\section{CONCLUSÕES}

As inundações graduais registradas por AVADANs e decretos municipais durante o período analisado eram mais frequentes nos anos 1980 e 1990 do que nos anos 2000, assim como as inundações associadas aos eventos de El Niño diminuíram. Nos períodos de El Niño as inundações 
além de serem mais recorrentes, também atingiam valores anormais, como é o caso do ano de 1983. Já nos anos 2000, foram muito mais recorrentes os períodos de inundações associadas à $L a$ Niña, e com isso as inundações bruscas se tornaram mais frequentes, contudo também se nota as inundações graduais são bem menos frequentes em períodos de La Niña e que as inundações bruscas são bem mais características para esta fase negativa do ENOS. Desta maneira, encontra-se uma relação direta entre as oscilações de temperatura no Oceano Pacífico e o regimento de inundações e o tipo de inundações que ocorreram na bacia do Rio do Peixe.

Ao comparar o uso e cobertura do solo dos anos 1970 e 2000 constatou-se que a tipologia de uso do solo não teve grandes mudanças, pois a presença de agropecuária continua sendo predominante na região. Somando-se a isso, a colonização que acontecia da região no final do século XIX dava ênfase ao extrativismo da madeira e posteriormente a agricultura, suinocultura, avicultura e silvicultura, não sendo recentes as alterações na bacia. Apesar dos tipos de uso e cobertura do solo dos anos 1980 até 2010 não serem diferenciadas, porém há uma extensão dos centros urbanos que promoveram a impermeabilização do solo e a ocupação do solo de forma negligente em alguns pontos.

Contudo, não há insumos suficientes para alegar que o aumento da população está diretamente relacionado com as inundações e os estudos com o uso e ocupação do solo também não foram suficientes para destacar as razões para a alteração dos registros. Embora o estudo com o uso e ocupação não tenha mostrado de forma clara as razões inundações, quando se analisa juntamente áreas com registros de inundações com a morfologia da bacia é perceptível uma relação. A locação dos centros urbanos dos municípios está diretamente ligada com rio, com a baixada do rio e com meandros sinuosos dos rios.

Também é preciso lembrar que os AVADANs e os decretos municipais para casos de desastres naturais somente são gerados quando há perdas e danos materiais e sociais, assim em caso de ocorrência do fenômeno de inundação que não haja vítimas ou prejuízos, os registros não são elaborados, pois neste caso o fenômeno é considerado apenas como ocorrência natural. Necessita-se assim pesquisas para esta região que levassem em consideração a morfologia dos rios, os tipos de cultivos plantados e sua relação com o escoamento superficial, as variações de precipitações ao longo destes últimos trinta anos. Outras variáveis climáticas também poderiam ser consideradas, como a Oscilação Decenal do Pacífico, para melhor compreender a razão de apenas inundações bruscas terem sido registradas a partir dos anos 2000 . Sugere-se também que seja esclarecida a metodologia utilizada na elaboração de AVADANs, do que é considerado inundação brusca e o que é gradual.

\section{REFERÊNCIAS}

CASTRO, A. L. C. DE, 2007. Desastres naturais relacionados com o incremento das precipitações hídricas e com as inundações. Em: CASTRO, ANTÔNIO LUIZ COIMBRA DE. Manual de desastres: desastres naturais. Brasília (DF): Ministério da Integração Nacional: 34-48.

\section{CENTRO DE PREVISÃO DE TEMPO E ESTUdOS CLIMÁTICOS. INSTITUTO NACIONAL DE PESQUISAS ESPACIAIS - CPTEC/} INPE. El Niño e La Niña. http://enos. cptec.inpe.br/ 
CHRISTOFOLETTI, A., 1980. Geomorfologia. 2.ed. rev. e ampl. São Paulo (SP): Edgard Blücher, 188p.

GEOAMBIENTE, FATMA/PPMASC, 2008. Mapeamento Temático Geral do Estado de Santa Catarina. Relatório Técnico: GEO-RLT-C0715-33608-01. Florianópolis.

HERRMANN, M. L. DE PAULA, 2014. Atlas de Desastres Naturais do Estado de Santa Catarina: período de 1980 a 2010. 2. ed. atual. e rev.- Florianópolis: IHGSC/ Cadernos Geográficos. 219 p.

INSTITUTO BRASILEIRO DE GEOGRAFIA E ESTATÍSTICA - IBGE, 1973. Carta topográfica de Caçador. Folha SG-22-Y-B-VI, escala 1:100.000. Primeira edição.

INSTITUTO BRASILEIRO DE GEOGRAFIA E ESTATÍSTICA - IBGE, 1976a. Carta topográfica de Joaçaba. Folha SG-22-Y-D-II, escala 1:100.000. Primeira edição.

INSTITUTO BRASILEIRO DE GEOGRAFIA E ESTATÍSTICA - IBGE, 1976b. Carta topográfica de Videira. Folha SG-22-Y-D-III, escala 1:100.000. Primeira edição.

KHAMIS, M. \& C. OSORIO, 2013. América del Sur: Uma visión regional de la situación de riesgo de desastres. Ayuda Humanitaria y Protección Civil, Oficina de las Naciones Unidas para la Redución del Riesgo de Desastres. http://www.eird.org/ wikiesp/images/Visi\%C3\%B3n_regional_ de_la_situaci\%C3\%B3n_de_riesgo_de_ desastres_America_del_Sur_FINAL.pdf.

KOBIYAMA, M.; B. BRANDENBURG; R. F. GOERL \& W. N. SILVEIRA, 2009.
História das Inundações em Joinville: 1851 2008. 01. ed. Curitiba: Organic Trading, 1: $153 \mathrm{p}$.

LOPES, A. R. DE BRITTO COSTA, 2012. Recursos hídricos e uso da terra na bacia do Rio do Peixe/SC, mapeamento das áreas de vulnerabilidade e risco de contaminação do sistema aquífero Serra Geral. 317 p. Tese (Doutorado) Universidade Federal de Santa Catarina, Centro de Filosofia e Ciências Humanas. Programa de Pós-graduação em Geografia.

MENDONÇA, F. DE A. \& I. MORESCO DANNI-OLIVEIRA, 2007. Climatologia: noções básicas e climas do Brasil. São Paulo: 206p.

NOAA - NATIONAL OCEANIC AND ATMOSPHERIC ADMINISTRATION. Climatic Prediction Center. Cold \& Warm Episodes by season. http://www.cpc. noaa.gov/products/analysis_monitoring/ ensostuff/ensoyears.shtml.

ORGANIZATION OF AMERICAN STATES - OAS, 1991. Primer on Natural Hazard Management in Integrated Regional Development Planning, comprehensive reference work on natural hazards management. http://www.oas.org/ osde/publications/Unit/oea66e/begin.htm.

SANTA CATARINA, 2006. Secretaria de Estado de Agricultura e Desenvolvimento Rural. Secretaria de Estado de Desenvolvimento Sustentável. Panorama dos Recursos Hídricos em Santa Catarina. Programa de Recuperação Ambiental e de Apoio ao Pequeno Produtor Rural PRAPREM/Microbacias 2: 231p.

SPINELLI, K., 2012. Variabilidade Pluviométrica na Bacia Rio do Peixe - 
Santa Catarina. Dissertação (Mestrado). Programa de Pós-Graduação em Geografia. Universidade Federal de Santa Catarina. Florianópolis.

TUCCI, C. E. M. \& J. C. BERTONI, 2003. (Ed.) Inundações urbanas na América do Sul. Porto Alegre: Associação Brasileira de Recursos Hídricos: 471p.
UNIVERSIDADE FEDERAL DE SANTA CATARINA, CENTRO UNIVERSITÁRIO DE ESTUDOS E PESQUISA SOBRE DESASTRES UFSC/CEPED, 2012. Atlas brasileiro de desastres naturais 1991 a 2010: volume Brasil / Centro Universitário de Estudos e Pesquisas sobre Desastres. Florianópolis: CEPED UFSC: $94 \mathrm{p}$. 